\title{
CORRESPONDENCE
}

\section{A LEAFLET FOR PARENTS OF STILLBORN CHILDREN}

Dear Sir,

We, the undersigned, came together to see what might be done to help parents whose child is stillborn. We are concerned that parents in these difficult circumstances do not receive the help they need. We have prepared the following leaflet with this in mind, and invite your readers' comments and criticisms, which we will try and incorporate into the final leaflet so that parents may have a combined professional approach to their problem. Comments should be sent to Dr David Morris, 24 Wimpole Street, London $\mathrm{W}_{1} \mathrm{M} 7 \mathrm{AD}$.

R. W. Beard, Obstetrician.

Janer BeckLey, Foundation for the Study of Infant Deaths.

Dora Brack, Child Psychiatrist.

Colnn Brewer, BPAS Research Fellow.

Yvonne Grasg, The Compassionate Friends.

Avrn. M. Hrul, National Childbirth Trust Representative.

Hugh Jolly, Paediatrician.

Emmanuel Lewts, Psychiatrist.

Hazlanne Lewis, Social Worker.

SyzviA Limerick, Foundation for the Study of Infant Deaths.

Judy Liston, Ante-natal teacher.

David Morris, Paediatrician (Convenor).

Dan Sarrven, National Childbirth Trust Representative.

Ruchard Wirson, Paediatrician.

\section{The Leaflet}

These notes have been prepared to help you following your baby's death.

What is Stillbirth?

Stillbirth is the death of a baby in the last three months of pregnancy or during labour.

Why did your baby die?

Sometimes a reason for the baby's death is found at post-mortem examination, but very often no cause is found. Post-mortems are not done routinely on stillborn babies but should be done to try to find out why your baby died. This may be important to help your doctor to advise you about your next pregnancy.
Was your baby's death anybody's fault?

Everybody is upset when a stillbirth occurs. Parents, doctors and nurses experience a sense of failure, loss and grief, and wonder if the tragedy could have been avoided.

Parents, especially mothers, are likely to blame themselves and there is also a strong tendency for parents to blame the doctors and nurses. This is part of the grief and depression many people feel after suffering such a personal loss. It may help to talk to a doctor, a midwife or a health visitor about your thoughts and feelings. Talking with other mothers often helps.

\section{Is it more difficult to give birth to a stillborn baby?}

It is very distressing to carry a dead baby inside you. Although labour and delivery are the same for live and stillbirths, they may feel different because of the sense of waste in giving birth to a dead baby.

\section{Should you see and hold your baby?}

This is never an easy decision, and even though it is painful, it is worth thinking about. You and your husband have every right to see and hold your baby if you so wish. This may seem strange to some parents, although an obvious desire for others. The experience of holding your baby even though he is dead may make him a more real person to remember and in this way, may help you and your husband.

What will happen to my milk?

Mothers are often surprised and distressed to find that they produce milk even though their baby has died. You may find that for medical reasons you will not be given drugs to dry up your milk. You will stop producing milk quite quickly, but do not express the milk even if you feel uncomfortable, as expressing will stop the milk drying up. Your midwife or health visitor will be able to advise you how to relieve discomfort at this time.

\section{Registering the baby's death}

A stillbirth has to be registered with the Registrar of Births and Deaths, and the hospital will tell you what you have to do. It will help you to talk about your baby if you give him or her a name.

\section{Funeral and burial arrangements}

If you so wish, the hospital can arrange for your baby's burial without charge. Parents often find a funeral service and marking the grave or the place of cremation helpful to them in their loss. 


\section{Parents' grief}

Whenever someone we love dies we go through a period of grief and mourning. This also happens after a stillbirth, although parents may feel they are grieving for a child they have never known, especially if they have never seen the baby, because a stillbirth leaves the parents with an emptiness and a bewildering sense of a non-event. People grieve in different ways. After the first shock some people want to talk about the tragedy repeatedly while others want to withdraw into themselves. Some feel angry; others reproach themselves, and many women after a stillbirth feel inadequate and a failure as a woman. Many are excessively concerned over their other children, while some find themselves unable to cope with them. These are normal reactions which generally lessen in time. Most important is to recognize that it is better to let yourself grieve and express your sorrow. When parents feel depressed, talking to another parent who has suffered a stillbirth can help and so can talking to others whom they feel are understanding, such as a doctor, chaplain, social worker or health visitor. It can help to make a marriage deeper and stronger if parents share their grief.

Children's reactions to stillbirth

Children are sensitive and share the family's loss. They may not understand or talk about death in the same way as an adult. Stillbirths are especially difficult for them because the baby they expected has disappeared. They may not be able to talk about their fears, and the younger ones cannot understand explanations. They need to be reassured of their parents' love and affection, however difficult it may be for parents at the time. It helps to explain the facts to them, and allows them to express their feelings of sadness, anger or bewilderment. Ghildren are often less afraid of death than adults and are more upset by disappearance. It is less frightening for children to tell them the truth than to leave them in ignorance at the mercy of their imagination. Children may need to be reassured that they were not the cause of the baby's death. Some children become difficult instead of showing their grief, while others may only allow their distress to come out later. Help is available from your family doctor, who may refer you to a paediatrician, a medical social worker at the hospital or to a Child Guidance Glinic.

What about another pregnancy? When to have another baby? Where to have your next baby?

Your obstetrician or family doctor will advise you about this, but it is advisable to wait a few weeks or even longer before starting another baby. Don't let yourself be pushed into having another baby but wait until you are ready. People are often unaware of how deeply and for how long some parents can mourn a stillborn child. Neighbours, friends and relatives may not understand your grief and are often embarrassed to talk to you about the baby. The deep feelings that are brought to the surface by a stillbirth often lead to family disagreements that you should not take too seriously. You should discuss with your family doctor where to have your next baby. You may be happier to return to the obstetrician you already know but do not feel guilty if you find you prefer to go elsewhere if you have unpleasant memories of the events surrounding your loss.

\section{Anxieties during your next pregnancy}

You are bound to be anxious about your next baby. Make sure that your family doctor knows what has happened and see him as frequently as you need to. Explain to friends and relatives you may need them any time you feel worried. The right company, or even a chat on the telephone, can calm fears. If you have other children, they may become anxious during your next pregnancy, and although they may not show it they may need the opportunity to talk about it. There is a great sense of joy and relief when the next baby is born safely, alive and well, but there can be unexpected and bewildering reactions. Some react either by being totally absorbed in the baby or feeling unreal and unable to care for him. Some parents over-protect the new baby. It is not uncommon and quite normal for parents to find themselves crying for the baby that died and grieving anew, while loving and cuddling their newborn baby.

\section{Reactions of others to the next baby's birth}

Most people are delighted when you have your next baby and often assume that you will then forget that you ever had a stillbirth. Don't let these reactions interfere with you enjoying your new baby.

\section{BIOLOGIGAL PSYGHIATRY GROUP}

\section{Dear Sir,}

There seems to be general agreement on the value of having Specialist Sections or Groups in the Royal College of Psychiatrists to arrange meetings and encourage the study of special aspects of psychiatry. Recently it has been suggested that in addition to the present Sections it might be helpful to have a Section for Biological Psychiatry, which would deal mainly with the biological approach and the application of the basic neurosciences to psychiatric problems. Thus the meetings of a Section of this kind might promote 